Jurnal Tabarru' : Islamic Banking and Finance

Volume 3 Nomor 2, November 2020

p-ISSN 2621-6833

e-ISSN 2621-7465

\title{
PROFITABILITAS KSPPS BMT NU CABANG LARANGAN PAMEKASAN TAHUN 2018
}

\author{
Ach. Zuhri \\ Jurusan Manajemen, Universitas Bahaudin Mudhary Madura \\ Email : ach.zuhri@unibamadura.ac.id
}

\begin{abstract}
ABSTRAK
Profitabilitas merupakan salah satu cara dalam mengukur dan melihat besarnya laba, untuk mengetahui seberapa efisien suatu perusahaan dalam menjalankan usahanya. Cara mengetahui besar kecilnya tingkat profitabilitas bank yaitu dengan menggunakan Return on Assets (ROA), ROA menunjukkan kapabilitas perusahaan menggunakan seluruh aktiva yang perusahaan miliki dalam menghasilkan keuntungan setelah pajak. Rasio ini sangat penting bagi pihak manajemen perusahaan untuk mengevaluasi efektivitas dan efisiensi usaha dalam mengelola seluruh pendapatan perusahaan. BMT NU saat ini telah tergolong berkembang pesat, dapat dilihat dari pertama berdirinya modal awal dari BMT NU yaitu tanggal 1 Juli 2004 hanya Rp. 400 ribu saja, berkat kerja keras pengurus dan anggota BMT NU waktu itu sehingga terbukti pada akhir tahun buku 2006 jumlah asset BMT NU sudah mencapai Rp. 30.361.230. Metode penelitian ini menggunakan pendekatan kuantitatif, sumber data yang peneliti gunakan menggunakan sumber data sekunder yang diambil dari laporan Rapat Anggota Tahunan (RAT) BMT NU Cabang Larangan tahun 2018. Hasil penelitian menunjukkan berdasarkan analisis data penelitian yang telah peneliti lakukan menggunakan Return on Assets dengan menjumlahkan antara laba bersih setelah dikurangi pajak dibagi dengan total aset mendapatkan hasil sebesar 2,81\%. Dilihat dari hasil analisis tersebut tingkat Return on Asset yang ada di KSPPS BMT NU Cabang Larangan masih tergolong kurang baik karena berada pada kriteria antara $1 \%$ s.d 3\%. Dapat diartikan bahwa BMT NU Cabang Larangan kurang baik dan kurang mampu mengelola hasil investasinya pada aset menjadi keuntungan atau laba.
\end{abstract}

Kata kunci : Profitabilitas, ROA, BMT.

\begin{abstract}
Profitability as a reference in measuring the amount of profit is very important to find out whether the company is running its business efficiently. How to find out the size of the level of bank profitability, one of which is Return on Assets (ROA), ROA shows the company's ability to use all its assets to generate profit after tax. This ratio is important for management to evaluate the effectiveness and efficiency of company management in managing all company assets. BMT NU is currently classified as rapidly developing, this can be seen from the initial capital establishment of BMT NU, namely on July 1, 2004, only Rp. 400 thousand alone, thanks to the hard work of the BMT NU management and members at that time, it was proven that at the end of the 2006 financial year the total assets of BMT $N U$ had reached $R p$. 30,361,230. This research method uses a quantitative approach, the data source that the researcher uses uses secondary data sources taken from the 2018 Annual Meeting of Members (RAT) of the BMT NU Larangan Branch. The results show that based on the analysis of research data that researchers have done using Return on Assets with adding up the net income after tax divided by the total assets gets the result of $2.81 \%$. Judging from the results of the analysis, the level of Return on Asset in the KSPPS BMT NU Larangan Branch is still classified as poor because it is in the criteria between 1\% to 3\%. It can be interpreted that BMT NU Cabang Larangan is not good enough and is not able to convert its investment in assets into profit or profit.
\end{abstract}

Keywords : Profitability, ROA, BMT. 


\section{PENDAHULUAN}

Bank adalah suatu lembaga yang berfungsi sebagai perantara antara pihakpihak yang mempunyai dana dengan pihak-pihak yang membutuhkan dana serta sebagai lembaga yang berperan nmemperlancar aliran lalu lintas pembayaran. Selain itu, bank juga sebagai suatu perusahaan yang dalam kegiatan usahanya mengandalkan kepercayaan masyarakat sehingga tingkat kesehatan bank harus dipelihara (Yunita, 2014).

Berdasarkan pasal 5 UndangUndang No 10 Tahun 1998, tentang Perbankan, terdapat 2 jenis bank, yaitu Bank Umum dan Bank Perkreditan Rakyat (Habibie, 1998). Dua jenis bank tersebut dalam menjalankan aktivitas usahanya diklasifikasikan menjadi dua, yaitu bank syariah dan bank konvensional. Perbedaan mendasar antara bank syariah dan bank konvensional yaitu bank konvensional menganut sistem bunga dalam transaksinya, sedangkan bank syariah melarang adanya bunga dalam transaksinya, bank syariah hanya menganut sistem profit and loss sharing (bagi hasil).

Bagian keuangan adalah bagian utama perusahaan. Jika posisi keuangan perusahaan di bawah standar, maka reputasi perusahaan menurun dan akibatnya investor, pemilik, pihak luar dan pemerintah juga kehilangan keuntungannya masing-masing (Das, 2018). Tujuan utama dari sebuah unit bisnis yaitu untuk mendapatkan keuntungan. Analisis profitabilitas dilakukan untuk menyoroti kinerja operasi dan efisiensi perusahaan bisnis saat ini. Perlu dicatat bahwa angka keuntungan bersih saja tidak terlalu membantu dalam menentukan efisiensi dan kinerja perusahaan bisnis kecuali jika dikaitkan dengan beberapa angka lain seperti penjualan, biaya operasi, harga pokok penjualan, modal yang diinvestasikan dll.
Dengan demikian rasio profitabilitas dihitung untuk mencerahkan hasil akhir dan perbandingan perusahaan bisnis yang merupakan satu-satunya kriteria efisiensi keseluruhan urusan bisnis (Tulsian, 2014).

Profitabilitas merupakan salah satu cara dalam mengukur dan melihat besarnya laba, untuk mengetahui seberapa efisien suatu perusahaan dalam menjalankan usahanya. Sebuah usaha baru dapat diketahui tingkat efisiensinya setelah membandingkan keuntungan yang diperoleh dengan modal yang menghasilkan keuntungan tersebut. Profitabilitas biasanya mengacu pada kemampuan bisnis untuk menghasilkan keuntungan (Zhang \& Wen, 2017).

Cara mengetahui besar kecilnya tingkat profitabilitas bank yaitu salah satunya yaitu dengan menggunakan rasio Return on Assets (ROA), Semakin tinggi nilai dari ROA itu berarti semakin bagus pula badan usaha dalam menggunakan assetnya untuk mendapatkan laba (Almira \& Wiagustini, 2020).

Dalam upaya mempertahankan dan mengembangkan perusahaannya, tidak hanya lembaga bank saja yang berusaha agar laba perusahaannya meningkat, namun lembaga non bank juga berupaya agar laba yang dihasilkannya bisa meningkat secara maksimal. Salah satu lembaga keuangan non bank yang berupaya menciptakan laba yang tinggi, bisa bertahan dan berkembang saat ini yaitu KSPPS BMT NU. BMT NU saat ini sudah tergolong berkembang pesat, hal ini dapat dilihat dari pertama berdirinya modal awal dari BMT NU yaitu tanggal 1 Juli 2004 hanya Rp. 400 ribu saja, berkat kerja keras pengurus dan anggota BMT NU waktu itu sehingga terbukti pada akhir tahun buku 2006 jumlah aset BMT NU telah mencapat Rp. 30.361.230. kemudian sampai Februari 2019 ini aset BMT NU telah mencapai Rp. 223 milyar 
(Wawancara awal bersama Andi Karyawan BMT NU).

Berdasarkan latar belakang tersebut, maka tujuan dari penelitian ini yaitu untuk mengetahui profitabilitas KSPPS BMT NU Cabang.

\section{TINJAUAN PUSTAKA}

\section{Profitabilitas}

Profitabilitas yaitu kemampuan perusahaan dalam menghasilkan laba dalam bentuk keuntungan yang mencerminkan laba dari investasi keuangan (Sabrin, Sarita, S, \& Sujono, 2016). Profitabilitas juga memiliki arti penting dalam suatu upaya mempertahankan keberlangsungan hidup usahanya dalam jangka panjang, karena profitabilitas dapat menunjukkan apakah badan usaha mempunyai prospek yang baik di masa akan datang. Dengan demikian setiap lembaga badan usaha akan selalu berupaya meningkatkan profitabilitasnya, keberlangsungan hidup badan usaha tersebut akan lebih terjamin jika tingkat profitabilitasnya semakin tinggi.

Profitabilitas akan memberikan pandangan yang lebih akurat tentang kinerja perusahaan. Pandy dalam (Amirthalingham \& Balasundaram, 2013) menunjukkan bahwa pengalaman barubaru ini di negara-negara dengan ekonomi terencana total menunjukkan bahwa ekonom mungkin benar dalam menekankan pentingnya profitabilitas keseluruhan sebagai kriteria untuk operasi yang efisien dari suatu perusahaan.

Cara mengetahui besar kecilnya tingkat profitabilitas bank yaitu salah satunya yaitu dengan menggunakan rasio Return on Assets (ROA), ROA adalah rasio yang bisa digunakan untuk menilai profitabilitas manajemen bank atau non bank sehingga perlu dijaga besarnya (Satiawati \& Munandar, 2020). ROA adalah faktor internal yang biasa digunakan untuk mengukur efektifitas dan efisiensi perusahaan untuk menghasilkan laba menggunakan aset yang dipunyai (Atidhira \& Yustina, 2017).

Setiap badan usaha berusaha supaya nilai dari ROA perusahaan mereka tinggi. Semakin tinggi nilai dari ROA itu berarti semakin baik pula badan usaha menggunakan assetnya untuk mendapatkan laba (Almira \& Wiagustini, 2020). ROA menunjukkan kapabilitas perusahaan menggunakan seluruh aktiva yang perusahaan miliki dalam menghasilkan keuntungan setelah pajak. Rasio ini sangat penting bagi pihak manajemen perusahaan untuk mengevaluasi efektivitas dan efisiensi usaha dalam mengelola seluruh pendapatan perusahaan. Semakin besar nilai ROA, mengartikan bahwa semakin efisien pula penggunaan aktiva perusahaan. Dengan kata lain, dengan jumlah modal/aktiva yang sama dapat dihasilkan keuntungan yang lebih besar, dan sebaliknya (Sudana, 2011).

Semakin tinggi tingkat profitabilitas perusahan yang dianalisis menggunakan ROA, maka akan semakin menarik minat investor. Sesuai dengan hasil penelitian yang telah dilakukan oleh (Atidhira \& Yustina, 2017) yang mengungkapkan bahwa variabel Return on Asset (ROA), Debt to Equity Ratio (DER) Earnings per Share (EPS) dan ukuran Perusahaan dapat dijadikan acuan, baik oleh manajemen perusahaan maupun oleh investor dalam menentukan strategi investasi.

\section{METODE PENELITIAN}

Metode penelitian ini menggunakan metode penelitian kuantitatif deskriptif, populasi pada penelitian ini yaitu data keuangan tahap laporan triwulan di KSPPS BMT NU Cabang Larangan Pamekasan, sedangkan sampelnya menggunakan data keuangan tahap laporan triwulan tahun 2018. 
Data yang peneliti gunakan menggunakan data sekunder, pengumpulan data dilakukan dengan cara mendatangi langsung ke lokasi penelitian yang terletak di Dusun Tomang Mate, Desa Blumbungan, Kecamatan Larangan, Kabupaten Pamekasan kemudian meminta data keuangan KSPPS BMT NU Cabang Larangan berdasarkan data tahunan tahun 2018. Analisis data dihitung berdasarkan rasio menggunakan rumus:

Return on Assets $(\mathrm{ROA})=($ earning after taxes)/(total assets) X 100\%

\section{HASIL DAN PEMBAHASAN}

Menurut Pandia ROA merupakan suatu indikator kemampuan perbankan dalam mendapatkan laba atas sejumlah aset yang dimiliki oleh bank. Semakin besar Return on Asset (ROA) pada bank maka semakin besar keuntungan yang diraih oleh bank tersebut, juga semakin bagus pula posisi bank dari segi penggunaan asset (Pandia, 2012).

Profitability ratio mengukur kemampuan lembaga usaha untuk menghasilkan keuntungan dengan menggunakan sumber-sumber yang dipunyai oleh perusahaan, seperti modal, atau penjualan perusahaan. Terdapat beberapa cara untuk mengukur tingkat profitabilitas, dalam penelitian ini peneliti hanya akan menggunakan analisis profitabilitas menggunakan Return on Assets dengan ketentuan rumusnya sebagai berikut:

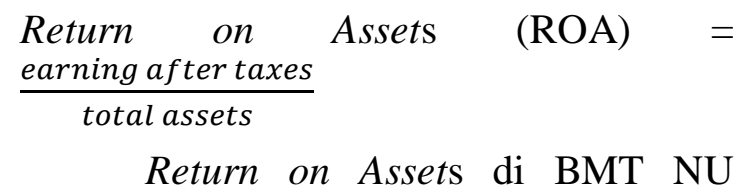
Cabang Larangan Pamekasan tahun 2018 yaitu:

Return on Assets $=\frac{139.068 .312,69}{4.944 .133 .457,61}$

Return on Assets = 2,81\%

Berdasarkan analisis data penelitian yang telah peneliti lakukan menggunakan Return on Assets dengan menjumlahkan antara laba bersih setelah dikurangi pajak dibagi dengan total asset mendapatkan hasil sebesar $2,81 \%$.

Analisis rasio berdasarkan Peraturan Menteri Negara Koperasi dan Usaha Kecil dan Menengah Nomor: 06/Per/M.KUKM/V/2006 untuk mengukur tingkat kinerja KSPPS BMT NU Cabang Larangan tentang pedoman penilaian koperasi berprestasi/koperasi award.

$$
\begin{array}{ll}
\text { Return } & \geq 10 \% \text { nilai }=100 \text { kriteria } \\
\text { on Asset } & \text { sangat baik } \\
& 7 \% \text { s.d }<10 \% \text { nilai }=75 \\
& \text { kriteria baik } \\
& 3 \% \text { s.d }<7 \% \text { nilai }=50 \\
& \text { kriteria cukup baik } \\
& 1 \% \text { s.d }<3 \% \text { nilai }=50 \\
& \text { kriteria kurang baik } \\
& <1 \% \text { nilai }=0 \text { kriteria tidak } \\
& \text { baik }
\end{array}
$$

Dilihat dari hasil analisis di atas tingkat Return on Asset yang dihasilkan oleh KSPPS BMT NU Cabang Larangan masih tergolong kurang baik karena berada pada kriteria antara $1 \%$ s.d $3 \%$.

Berdasarkan hasil analisis di atas dengan Return on Asset KSPPS BMT NU Cabang Larangan tahun 2018 yang tergolong kurang baik, dapat dikatakan bahwa BMT NU Cabang Larangan kurang baik dan kurang mampu mengkonversi investasinya pada aset menjadi keuntungan atau laba. Umumnya pemanfaatan aset modal merupakan salah satu investasi yang dapat memperoleh keuntungan paling besar, namun BMT NU Cabang Larangan tidak bisa memanfaatkan asset modalnya secara optimal.

Profitabilitas KSPPS BMT NU Cabang Larangan kurang baik karena hasil perhitungan berdasarkan Return on Asset berada pada kriteria antara $1 \%$ s.d 
3\%. Artinya nilai dari KSPPS BMT NU Cabang Larangan masih kurang meyakinkan para pihak ketiga (Penabung, Investor, dan pihak lainnya), hal ini didasarkan pada hasil penelitian yang dilakukan oleh (Husna \& Satria, 2019; Rosikah, Prananingrum, Muthalib, Azis, \& Rohansyah, 2018) menunjukkan bahwa Return on Asset berpengaruh positif dan signifikan terhadap nilai perusahaan, dapat diasumsikan bahwa perolehan laba dapat menjadi indikator bagi investor untuk menanamkan sahamnya di perusahaan sehingga dapat mempengaruhi nilai perusahaan.

Pentingnya meningkatkan
profitabilitas berdasarkan ROA
didapatkan dari hasil penelitian yang
dilakukan oleh (Heikal, Khaddafi, \&
Ummah, 2014) menunjukkan bahwa
terdapat pengaruh positif antara Return on
Asset dengan pertumbuhan laba, artinya
setiap peningkatan nilai Return on Asset
secara umum akan menyebabkan
peningkatan laba bagi perusahaan, dengan
meningkatnya kemampuan perusahaan
dalam menghasilkan pertumbuhan laba
akan memastikan bahwa laba perusahaan
akan meningkat karena ROA merupakan
rasio yang menunjukkan seberapa efektif
perusahaan menghasilkan laba operasi
bagi perusahaan.

Return on Assets ini dapat membantu tim manajemen dan para investor untuk melihat seberapa bagus suatu perusahaan mampu merubah dan mengatur investasinya pada asset menjadi keuntungan (profit). Tingkat Pengembalian Aset atau Return on Assets ini juga dapat diartikan sebagai tingkat pengembalian dari investasi (return on investment) bagi suatu lembaga usaha karena biasanya aset modal (capital assets) seringkali dikatakan investasi terbesar bagi perusahaan-perusahaan. Dengan kata lain, modal diinvestasikan menjadi suatu asset modal dan imbal hasilnya atau tingkat pengembaliannya dapat diukur dalam bentuk keuntungan (profit) yang didapat.

Hasil penelitian yang dilakukan oleh (Salawu, 2009) menunjukkan bahwa perusahaan di Nigeria bergantung pada pembiayaan eksternal. Dalam kasus Nigeria, sebagian besar $(60 \%)$ dari hutang diwakili dalam hutang jangka pendek. Studi tersebut menyarankan agar perusahaan menerapkan kebijakan perkreditan yang efektif dan efisien, yang akan meningkatkan tingkat kinerja perputaran dan pertumbuhan.

Semakin tinggi tingkat profitabilitas perusahan, maka akan semakin menarik minat investor. Hal ini sesuai dengan hasil penelitian yang telah dilakukan oleh (Atidhira \& Yustina, 2017) yang mengungkapkan bahwa variabel Return on Asset (ROA), Debt to Equity Ratio (DER) Earnings per Share (EPS) dan ukuran Perusahaan dapat dijadikan acuan, baik oleh manajemen perusahaan maupun oleh investor dalam menentukan strategi investasi.

\section{KESIMPULAN}

Berdasarkan hasil pembahasan di atas dapat disumpulkan bahwa tingkat profitabilitas berdasarkan perhitungan menggunakan Return on Asset tergolong kriteria kurang baik dengan hasil ROA= $2.81 \%$, KSPPS BMT NU Cabang Larangan harus meningkatkan nilai dari Return on Asset agar nilai profitabilitasnya juga meningkat, karena ROA dinilai merupakan rasio yang paling efektif perusahaan dalam menghasilkan laba. Semakin tinggi tingkat profitabilitas KSPPS BMT NU Cabang Larangan, maka semakin banyak investor yang akan menabung dan menginvestasikan modalnya.

\section{DAFTAR PUSTAKA}

Almira, N. P. A. K., \& Wiagustini, N. L. P. 2020. Return On Asset, Return On Equity, dan Earning Per Share 
Berpengaruh Terhadap Return Saham. E-Jurnal Manajemen, 9(3), 1069-1088.

Amirthalingham, N., \& Balasundaram, N. 2013. Determinants of Profitability: A Case Study of Listed Manufacturing Companies in Sri Lanka. Merit Research Journal of Art, Social Science and Humanities, 1(1), 001-006.

Atidhira, A. T., \& Yustina, A. I. 2017. The Influence of Return on Asset, Debt to Equity Ratio, Earnings per Share, and Company Size on Share Return in Property and Real Estate Companies. JAAF (Journal of Applied Accounting and Finance), 1(2), 128-146.

Das, S. C. 2018. Impact of Profitability on Capital Structure: An Analytical Study. International Journal of Trend in Scientific Research and Development, 2(4), 1354-1360.

Habibie, B. J. 1998. Undang-undang (UU) tentang Perubahan atas Undang-Undang Nomor 7 Tahun 1992 tentang Perbankan. Retrieved from https://peraturan.bpk.go.id/Home/De tails/45486/uu-no-10-tahun-1998

Heikal, M., Khaddafi, M., \& Ummah, A. 2014. Influence Analysis of Return on Assets (ROA), Return on Equity (ROE), Net Profit Margin (NPM), Debt To Equity Ratio (DER), and Current Ratio (CR), Against Corporate Profit Growth In Automotive In Indonesia Stock Exchange. International Journal of Academic Research in Business and Social Sciences, 4(12), 101-114.

Husna, A., \& Satria, I. 2019. Effects of Return on Asset, Debt to Asset Ratio, Current Ratio, Firm Size, and Dividend Payout Ratio on Firm Value. International Journal of
Economics and Financial Issues, 9(5), 50-54.

Pandia, F. 2012. Manajemen Dana dan Kesehatan Bank. Rhineka Cipta. Jakarta.

Rosikah, Prananingrum, D. K., Muthalib, D. A., Azis, M. I., \& Rohansyah, M. 2018. Effects of Return on Asset, Return On Equity, Earning Per Share on Corporate Value. The International Journal of Engineering and Science (IJES), 7(3), 06-14.

Sabrin, Sarita, B., S, D. T., \& Sujono. 2016. The Effect of Profitability on Firm Value in Manufacturing Company at Indonesia Stock Exchange. The International Journal Of Engineering And Science (IJES), 5(10), 81-89.

Salawu, R. O. 2009. The Effect of Capital Structure on Profitability: An Empirical Analysis of Listed Firms in Nigeria. The International Journal of Business and Finance Research, 3(2), 121-129.

Satiawati, R., \& Munandar, A. 2020. Analisis Kredit Macet terhadap Return on Asset (ROA) pada Koperasi Pegawai Negeri (KPN) Kasabua Ade Bima. Profitability: Jurnal Ilmu Manajemen, 4(2), 113119.

Sudana, I. M. 2011. Manajemen Keuangan Perusahaan : Teori dan Praktik. Erlangga. Jakarta.

Tulsian, M. 2014. Profitability Analysis (A Comparative Study of SAIL \& TATA Steel). IOSR Journal of Economics and Finance (IOSR$J E F), 3(2), 19-22$.

Yunita, R. 2014. Faktor-Faktor Yang Mempengaruhi Tingkat Profitabilitas Perbankan Syariah di Indonesia (Studi Kasus Pada Bank 
2020, Jurnal Tabarru' : Islamic Banking and Finance 3 (2) : 262 - 268

Umum Syariah di Indonesia Tahun 2009-2012). Jurnal Akuntansi

Indonesia, 3(2), 143-160.

Zhang, M., \& Wen, J. 2017. Profitability analysis of KINGLONG Nearly 5

Years. IOP Conf. Series: Journal of Physics: Conf. Series 887. 